\title{
PREVALENCE OF MALOCCLUSION AND COMMON \\ OCCLUSAL TRAITS AMONG ADOLESCENT SCHOOL \\ CHILDREN IN DAKAHLIYA, EGYPT AND MAKKAH, SAUDI \\ ARABIA (A COMPARATIVE STUDY)
}

\author{
Hanaa M S El-Attar( ${ }^{(* 1)}$, Rabab I Salama ${ }^{(2)}$, Aya S Hussien ${ }^{(3)}$
}

\begin{abstract}
The aim of this study was to assess the prevalence of malocclusion among adolescent school students in Dakafliya Governorate, Egypt and compare it to a similar group in Makkah Saudi Arabia. Furthermore, explore the possibility of the presence of significant difference between different population for the various occlusal traits assessed. Materials and Methods: Descriptive study with stratified cluster random sample of 627 male adolescents, with age range (14-17) years, selected from 21 schools in the Dakahliya Governorate, Egypt and Makkah, Saudi Arabia to asses and compare the status of occlusion. Occlusal traits assessed were; malocclusion types, crowding, diastema, cross bite, overjet and overbite. Results and Conclusion: This study revealed predominance of Angle Class I (67.1\% in Saudis, 65.4\% Egyptians), followed by Class II (div1) (14.5\%, 18.6\%), then Class II (div2) (10.7\%, 8.6\%). Class III showed the least prevalence $(7.6 \%, 7.4 \%)$ for Saudis and Egyptians respectively. The most prevalent malocclusion trait was crowding (63.3\% in Saudis, $57.7 \%$ in Egyptians). Increased overjet was higher among Egyptians. Decreased overjet was higher among Saudis. Increased overbite was more prevalent in Egyptians while decreased overbite was more prevalent in Saudis. Anterior and posterior crossbite showed more prevalence among Saudi adolescents. Where diastema was more prevalent among
\end{abstract}

Egyptians. Statistically significant difference was found between Saudi and Egyptian male adolescents in all the studied occlusal traits.

Keywords: Dental Health; Malocclusion, Prevalence, Dakahliya, Egypt, Makkah SA

\section{Introduction}

Malocclusion is not only a single entity but rather a collection of situations each can constitute a problem. Any of these situations are influenced by variety of factors both genetic and environmental [1]. Malocclusion as a term describes mis-alignment or improper relationship between the teeth and/or the dental arches, when the jaws approach each other. It is a continuous spectrum of occlusal variation, with wide scope of severity and implications in creating an alternative form of occlusion [2].

According to $\mathrm{WHO}$, malocclusion is ranked third most frequent disease of the oral health, after periodontitis and dental caries [3]. Malocclusion may result in unpleasant appearance, impairment in speech, and oral function, Tempro-mandibular disorders or increased the susceptibility to trauma and periodontal disease [4]. Planning orthodontic treatment service requires baseline data on the prevalence of the different types of malocclusion. Several studies investigated the prevalence of malocclusion in different

1* Lecturer of Orthodontics, Faculty of Dentistry, Suez Canal University, Ismailia, Egypt

2 Assistant Professor of Dental Public Health and Preventive Dentistry, Faculty of Dentistry, Mansoura University, Egypt

3 Dental Intern, Faculty of Dentistry, Mansoura University, Egypt 
population groups. The results of these studies showed that these populations vary widely. The variations could be due to the differences in ethnic backgrounds, sampling size, subjects age, and/or examination methods [4-20]. Identification of the occlusal status for a particular population provides an important information that assists governments planning the appropriate preventive and treatment programs [5].

In Egypt, few studies investigated the prevalence of malocclusion; among primary school children, in Cairo governorates [21], another study in 1990 was conducted on adults [21]. Abd ElMotaleb et al reported the prevalence of anterior open bite among Egyptian adolescent [22]. In 2017 a systematic review on the global distribution of malocclusion traits was published, the data involving the Egyptian population was limited [23].

Egypt and Saudi Arabia are large countries with population from different ethnic backgrounds. The present study will try to draw a pattern for the malocclusions among normal adolescents not seeking orthodontic treatment within Dakahliya including the major cities (Mansoura, Simbilaween and Mitghamer) harvesting most of the population in this Governorate and compare it to results obtained by the author from a sample on a similar population group in Makkah Saudi Arabia [24].

Based on ethnic/socio-economic differences, orthodontic treatment in different populations, usually have several levels of treatment need. It can be considered as a relative concept that is not comparable between different populations [19-25]. therefore, considerations should be taken to provide proper preventive and interceptive orthodontic services to the affected group [1].
This study was conducted aiming to assess the prevalence of malocclusion among male adolescents from secondary school students in Dakahliya Governorate, Egypt and compare it to a similar group in Makkah SA. Furthermore, explore the possibility of the presence of significant difference between both populations for in the various occlusal traits assessed in this study.

\section{Materials and methods}

This was a cross-sectional study with a sample of (627), 289 male Saudi and 338 male Egyptian's adolescents, with age range (14-17) years. Ethical approval was obtained from the Institutional Review Board, Mansoura Faculty of Dentistry and UQU, Faculty of Dentistry, the purpose and design of the study were explained and written informed consents were signed by the participants' parents before the examination. Approval from the educational governorate was obtained to facilitate the data collection from students during the school days. Data was collected over 3 months period.

\section{Sample size calculation}

Sample size was calculated using (https://surveysystem.com/sscalc.htm ) online calculator, at confidence interval $95 \%$ and confidence level 5 the sample size was 302 subjects for each location. For Saudi students the actual sample was (289) as (20) students were excluded as not following the inclusion criteria or did not sign the informed consent. For Egyptian students, (338) signed the consents and followed the inclusion criteria.

\section{Subjects}

The students were randomly selected using stratified random sample from (21) secondary schools both from Dakahliya, Egypt and Makkah, Saudi Arabia. The subjects were selected according to the following Inclusion 
criteria :No previous orthodontic treatment. Presence of first permanent molar with no remaining deciduous teeth. No pervious extraction or dental carious lesions that causes change in the tooth size or shape

\section{Data collection}

An intraoral examination of the participating students was conducted by three trained and calibrated examiners in the selected school's compounds using natural day lighting, disposable wooden spatula and orthodontic millimeter rulers. Angle Classification System was used to identify the occlusion relation [26]. Presence of crowding, overbite or overjet was recorded [27]. Measuring the anterior cross bite and/or posterior cross bite [28] and presence of anterior diastema [29]. The collected data were recorded in a predesigned malocclusion registration chart, as following table:

\begin{tabular}{|c|l|}
\hline Variable & Method of measurement \\
\hline Sagittal occlusion & $\begin{array}{l}\text { Normal Occlusion (Angle class I) } \\
\text { Post- normal occlusion (Distocclusion, Angle class II) } \\
\text { Pre-normal occlusion (Mesiocclusion, Angle class III) }\end{array}$ \\
\hline Overjet & increased if it's more than $3 \mathrm{~mm}$, decreased if it's less than $2 \mathrm{~mm}$ \\
\hline Overbite & increased if it's more than $2 \mathrm{~mm}$, decreased if it's less than $2 \mathrm{~mm}$ \\
\hline Crowding & overlapping of on tooth with respect to another tooth \\
\hline Diastema & space more than 1 mm between central incisors \\
\hline Cross bite & $\begin{array}{l}\text { in one or more maxillary teeth are placed palatallingual to the } \\
\text { mandibular teeth }\end{array}$ \\
\hline
\end{tabular}

\section{Validity of the data}

The clinical examination was performed by three examiners, they were trained and calibrated to ensure consistency of the examination. kappa reliability coefficient with a value of 0.93 and 0.91 for intra and inter examiner variability, respectively, were indicating strong agreement.

\section{Statistical Analysis}

The data was analyzed statistically using the SPSS statistical package (Statistical Package for the Social Sciences Version 20.0, SPSS, Inc., Chicago, Ill, USA). Chi square test was performed to test the significance, $p$ value less than or equal 0.05 was found to be of statistical significance. 


\section{Results}

Table (1). Distribution of Angle Classes of malocclusion among Saudi and Egyptian male adolescents.

\begin{tabular}{|l|c|c|c|}
\hline Angle Class & $\begin{array}{c}\text { Saudi } \\
\mathrm{N}(\%)\end{array}$ & $\begin{array}{c}\text { Egyptian } \\
\mathrm{N}(\%)\end{array}$ & $\begin{array}{c}\text { Chi square } \\
\text { ( p value) }\end{array}$ \\
\hline Class I & $194(67.1 \%)$ & $221(65.4 \%)$ & \\
\hline Class II (div.1) & $42(14.5 \%)$ & $63(18.6 \%)$ & \multirow{2}{*}{$4.328^{*}$} \\
\cline { 1 - 3 } Class II (div.2) & $31(10.7 \%)$ & $29(8.6 \%)$ & $(0.05)$ \\
\hline Class III & $22(7.6 \%)$ & $25(7.4 \%)$ & \\
\hline Total & $289(100 \%)$ & $338(100 \%)$ & \\
\hline
\end{tabular}

$\mathrm{N}$ : Number of students $\quad \mathrm{p}$ : $\mathrm{p}$ value for comparing between the studied groups

*: Statistically significant at $\mathrm{p} \leq 0.05$

Regarding the Angle Classification, although

2) the percentages were higher among Saudi the percentages of distribution for the different classes of malocclusion were close between Saudi and Egyptian adolescents, statistical than Egyptian adolescents, where Class II (div 1) and Class III were higher among Egyptian than Saudi adolescents. (Table 1) difference was observed. In Class I and II (div

Table (2). Distribution of Overjet and Overbite among Saudi and Egyptian male adolescents.

\begin{tabular}{|c|c|c|c|c|c|c|}
\hline & \multicolumn{3}{|c|}{ Overjet } & \multicolumn{3}{|c|}{ Overbite } \\
\hline & $\begin{array}{l}\text { Saudi } \\
\mathrm{N}(\%)\end{array}$ & $\begin{array}{c}\text { Egyptian } \\
\mathrm{N}(\%)\end{array}$ & Total & $\begin{array}{l}\text { Saudi } \\
\mathrm{N}(\%)\end{array}$ & $\begin{array}{c}\text { Egyptian } \\
\mathrm{N}(\%)\end{array}$ & Total \\
\hline Normal & $\begin{array}{c}166 \mathrm{~m} \\
(57.4 \%)\end{array}$ & $\begin{array}{c}204 \\
(60.4 \%) \\
\end{array}$ & $59 \%$ & $\begin{array}{c}152 \\
(52.6 \%)\end{array}$ & $\begin{array}{c}167 \\
(49.4 \%)\end{array}$ & $50.9 \%$ \\
\hline Increase & $\vee 4(25.6 \%)$ & $90(26.6 \%)$ & $23 \%$ & $61(21.1 \%)$ & $93(27.5 \%)$ & $27.9 \%$ \\
\hline Decrease & $\varepsilon 9(1 \vee \%)$ & $44((13 \%)$ & $18 \%$ & $76(26.3 \%)$ & $78(23.1 \%)$ & $21.2 \%$ \\
\hline $\begin{array}{l}\text { Chi square } \\
\text { ( } \mathrm{p} \text { value) }\end{array}$ & \multicolumn{2}{|c|}{$\begin{array}{l}6.732 * \\
(0.03) \\
\end{array}$} & & \multicolumn{2}{|c|}{$\begin{array}{l}5.491 * \\
(0.05)\end{array}$} & \\
\hline
\end{tabular}


Regarding the overjet measurements, normal overjet was found in (60.4\%) of Egyptian students this percent was higher than that among Saudis (57.4\%). Increased overjet was higher among Egyptians (26.6\%) than Saudis $(25.6 \%)$. Decreased overjet was (17\%) among Saudis which was more prevalent than that among Egyptians (13\%). Statistically significant difference was found between Saudi and Egyptian adolescents regarding overjet measurements at $(\mathrm{p}=0.03)$. Regarding the overbite measurements, normal overbite was found in $(52.6 \%)$ of Saudi adolescents coming significantly higher than those of Egyptians $(49.4 \%)$. Increased and deceased overbite; $(27.5 \%, 23.1)$ were found among Egyptian adolescents respectively, while $(21.1 \%, 26,3 \%)$ were found among Saudis respectively. Increased overbite was more prevalent in Egyptians while decreased overbite was more prevalent in Saudis. Statistically significant difference was found between Saudi and Egyptian adolescents regarding the overbite measurements at $(\mathrm{p}=0.05)$. (Table2)

Table (3). Distribution of different malocclusion traits among Saudi and Egyptian male adolescents

\begin{tabular}{|c|c|c|c|}
\hline & $\begin{array}{l}\text { Saudi } \\
\mathbf{N}(\%)\end{array}$ & $\begin{array}{c}\text { Egyptian } \\
\mathbf{N}(\%)\end{array}$ & $\begin{array}{c}\text { Chi square } \\
\text { (p value) }\end{array}$ \\
\hline Crowding & $183(63.3 \%)$ & $195(57.7 \%)$ & $\begin{array}{l}5.046^{*} \\
(0.04)\end{array}$ \\
\hline Diastema & $24(8.3 \%)$ & $21(6.2 \%)$ & $\begin{array}{l}4.991 * \\
(0.05) \\
\end{array}$ \\
\hline $\begin{array}{l}\text { Anterior cross } \\
\text { bite }\end{array}$ & $49(17 \%)$ & $28(8.2 \%)$ & $\begin{array}{l}4.986^{*} \\
(0.05)\end{array}$ \\
\hline $\begin{array}{l}\text { Posterior cross } \\
\text { bite }\end{array}$ & $62(21.4 \%)$ & $32(9.5 \%)$ & $\begin{array}{l}5.103 * \\
(0.05)\end{array}$ \\
\hline
\end{tabular}

Table (3), showed the percentages of different types of malocclusion, crowding was the highest type observed $(63.3 \%, 57.7 \%)$ among Saudi and Egyptian male adolescents respectively. Anterior cross bite was shown in $(8.2 \%)$ of the Egyptian adolescents which was lower than that shown among Saudi ones (17\%). Posterior cross bite was (21.4\%) among Saudis, higher than that $(9.5 \%)$ among Egyptians. Regarding diastema, it was observed in (8.3\%) among Egyptians higher than that $(4.8 \%)$ among Saudis. Statistically significant difference was found between Saudi and Egyptian adolescents at $(\mathrm{p}=0.04)$ regarding different malocclusion anomalies.

\section{Discussion}

As per the WHO, epidemiologic surveys at regular interval should be conducted to determine the oral diseases. Orthodontics is a branch of the dental specialty that developed in early 1900s, and since then, various 
population-based surveys were done on malocclusion.incidence.

The present study was designed to assess the prevalence of malocclusion among male adolescent school students in Dakahliya Governorate, Egypt and compare it to a similar group in Makkah SA. Furthermore, explore the possibility of the presence of significant difference between both populations for the various occlusal traits assessed in this study. This will help providing baseline data about malocclusion in these districts in order to help health care planners designing the needed orthodontic services in the health care programs in near and far future.

The sample included subjects with an age range between 14 to 17 years depending on the fact that this age group will have permanent dentition to exclude the individual dental pattern variations usually existing during the mixed dentition that can affect the occlusion [30].

Common occlusal parameters were recorded; Angle's Classification was used to record anteroposterior inter-arch relationship. Main occlusal traits were assessed by recording crowding, overjet, overbite, diastema, anterior and posterior crossbite.

In present sample Angle Class I (67.1\% in Saudis, $65.4 \%$ Egyptians) was the most prevalent type of malocclusion followed by Class II (div1) $(14.5 \%, 18.6 \%)$, then Class II (div2) $(10.7 \%, 8.6 \%)$. Class III showed the least prevalence $(7.6 \%, 7.4 \%)$ for Saudis and Egyptians respectively. However, the percentage of distribution showed significant difference.

Similarity of the pattern of distribution was observed with reports from other countries. The percentage of distribution was different between populations, Class I relationship was the most frequent feature in; Americans (55\%) [31], Saudis (61\%) [32], Kuwaitis (57.8\%) [33], and Jordanians (92\%) [34], Libyans (66.5\%) [35], Nepalese (54.7\%) [36] and Pakistanis (59.9\%) [37], Nigerians $(80.7 \%)$ [1,38] and Tanzanians (93.6\%) [4], Iranians (52\%)[39] and Brazilians (76.7\%) [12], Class II followed and Class III came last in prevalence with variations in percentage.

The pattern of distribution was different from that reported by Kenyan [40], Turkish [17], and Anatolian [11] studies. In an adult sample from Kenya Class I was (70\%) followed by Class II Division 1(7.5\%), Class III and Class II Division 2 showed equal percentage of distribution at 5\% each [40]. In a Turkish sample Class I represented (64\%), Class II, division 1 (19\%), Class III (12\%), and Class II, division 2 was the least prevalent with $5 \%$ [17], where in the Anatolian study they reported Class II division 1 as being the most prevalent (40.0\%), Class I (34.9\%), Class III (10.3\%), Class II division 2 was the least common $(4.7 \%)$ [11].

The present study results for the Egyptian students came concurrent with those of ElMangoury et al [21] on Egyptian sample in 1990. The same pattern of distribution for the different Angle types of malocclusion applied with comparable percentages for all malocclusion Classes.

Crowding was the most prevalent occlusal trait within our sample $(63.3 \%$ in Saudis, $57.7 \%$ in Egyptians). These results were comparable to the results of Kuwaitis (70\%) [33], Jordanians (50.7\%) [34], Nepalese (65.7\%) [36], and Pakistanis (57.2\%) [37]. Sayin and Turkkahraman reported moderate maxillary crowding to be the most common finding in all malocclusion groups in a Turkish sample [17]. This comes in disagreement with Aikins and Onyeaso, who recorded spacing in 
$60 \%$ of Nigerian adults sample [38]. These differences may be attributed to different genetic and ethnic backgrounds of the collected sample.

Most adolescents in the present study had normal overjet and overbite. Normal overjet occurred more significantly in Egyptian students (57.4\% in Saudis, 60.4\% in Egyptians) whereas normal overbite was significantly more in Saudis $52.6 \%$ in Saudis, $49.4 \%$ in Egyptians). Normal overjet and overbite were also prevalent among Saudi sample from Riyad [5] and Jeddah [32], Tanzanians [4], Nigerians [1,38], Iranians [39], and Pakistanis [37]. Comparing Egyptian adolescents to the Saudi's; Increased overjet and overbite were significantly higher among Egyptians showing (26.6\% - 27.5\%) respectively, where decreased overjet and overbite were significantly higher among Saudis (17\% - 26.3\%).

Posterior cross bite was $21.4 \%$ in Saudi adolescents which was significantly higher than the Egyptians (9.5\%). Many populations showed high percentage for posterior crossbite; Brazilians reported (19.2\%) [12], Kuwaitis (26.2\%) [33], Nepalese (23,3\%) [36], and Iranians (36\%) [39]. These results can be comparable to Saudis, The Egyptian students showed a less occurrence in posterior crossbite $(9.5 \%)$ which is relatively similar to those reported among Jordanians (6.8\%) [34], Libyans (7.6\%) [35]. Pakistanis (3.8\%) [37]

Maxillary midline diastema was found in (8.3\% Saudis, 6.2\% Egyptians) the difference was significant. Comparable results were reported in Jordan (6.9\%) [34], and Turkey $(4.5 \%)$ [41].

Disagreement in findings between different studies could be attributed to differences in Ethnic backgrounds, registration methods, and/or sample size.

\section{Recommendation}

Although the present study achieved its objectives, we do recommend conducting further studies using large -scale surveys from different Egyptian and Saudi Governorates to formulate a national policy aiming for early intervention and prevention of malocclusion.

\section{Conclusion}

This study revealed predominance of Angle Class I (67.1\% in Saudis, 65.4\% Egyptians), followed by Class II (div1) $(14.5 \%, 18.6 \%)$, then Class II (div2) $(10.7 \%, 8.6 \%)$. Class III showed the least prevalence $(7.6 \%, 7.4 \%)$ for Saudis and Egyptians respectively. The most prevalent malocclusion trait was crowding (63.3\% in Saudis, $57.7 \%$ in Egyptians). Increased overjet was higher among Egyptians. Decreased overjet was higher among Saudis. Increased overbite was more in Egyptians while decreased overbite was more in Saudis. Anterior and posterior crossbite showed more prevalence among Saudi adolescents. Where diastema was more prevalent among Egyptians. Statistical significance difference was found between Saudi and Egyptian adolescents in all the studied occlusal traits.

\section{References}

1. Onyeaso CO. Prevalence of Malocclusion among adolescents in Ibadan, 
Nigeria. Am J Orthod Dentofacial Orthop. 2004;126: 604-7.

2. Bishara, Samir E., ed. Textbook of Orthodontics. Philadelphia:Saunders, 2001. 84-92.

3. Dhar V, Jain A, Van Dyke TE, Kohli A. Prevalence of gingival diseases, malocclusion and fluorosis in school-going children of rural areas in Udaipur district. J Indian Soc Pedod Prev Dent June 2007;25:103-5.

4. Mtaya M, Brudvik P, Astrøm AN. Prevalence of malocclusion and its relationship with socio-demographic factors, dental caries, and oral hygiene in 12 to 14-year-old Tanzanian schoolchildren. Eur J Orthod. 2009;31:467-76.

5. Asiry MA. Occlusal status among 1216-year-old school children in Riyadh, Saudi Arabia. J Int Oral Health. 2015;7:20-3.

6. Foster TD, Menezes DM. The assessment of occlusal features for public health planning purposes.Am. J.Orthod. 1976;69: 83-89.

7. Thilander B, Pena L, Infante C, Parada SS, De Mayorga C. Prevalence of malocclusion and orthodontic treatment need in children and adolescents in Bogota, Colombia. An epidemiological study related to different stages of dental development. Eur J Orthodont. 2001;23:153-17.

8. Harisson RL, Davis DW. Dental malocclusion in native children of British Columbia, Canada. Community Dent Oral Epidemiol. 1996;24:217-21.

9. Gardiner JH. An orthodontic survey of Libyan schoolchildren. Br J Orthod. 1982;9:59-61.

10. Garner LD, Butt MH. Malocclusion in Black Americans and Nyeri Kenyans. An epidemiologic study. Angle Orthod 1985;55:139-46.

11. Bilgic F, Gelgor IE, Celebi AA. Malocclusion prevalence and orthodontic treatment need in central Anatolian adolescents compared to European and other nations' adolescents. Dental Press J Orthod. 2015;20:75-81.

12. Grando G, Young AA, VedovelloFilho M, Vedovello SA, Ramirez-Yanez GO. Prevalence of malocclusions in a young Brazilian population. Int J Orthod. 2008;19:13-6.

13. Grewe JM, Cervenka J, Shapiro BL, Witkop CJ, Jr. Prevalence of malocclusion in Chippewa Indian children. J Dent Res 1968;47:302-5.

14. Hill, P.A. The prevalence and severity of malocclusion and the need for orthodontic treatment in 9, 12, and 15-year-old Glasgow schoolchildren. Br J Orthod. 1992; 19, 87-96.

15. Johannsdottir B, Wisth PJ. Magnusson TE. Prevalence of malocclusion in 6-year-old Icelandic children. A study using plaster models and orthopantomograms. Acta Odontologica scandinavica. 1997;55:398-402.

16. Lew KK, Foong WC, Loh E. Malocclusion prevalence in an ethnic Chinese population. Aust Dent J. 1993;38:442-9.

17. Sayin MO, Turkkahraman $H$. Malocclusion and crowding in an orthodontically referred Turkish population. Angle Orthod. 2004;74:635-9.

18. Silva RG, Kang DS. Prevalence of malocclusion among Latino adolescents. Am J Orthod Dentofacial Orthop. 2001;119:313-5.

19. Al-Emran S, Wisth PJ, Böe OE. Prevalence of malocclusion and need for orthodontic treatment in Saudi Arabia. Community Dentistry and Oral Epidemiology. 1990;18:253-5.

20. El Sayed F, Fsifis M, Munir H. Prevalence of malocclusion in school children in Cairo, Egypt. (A Survey Study). Egyp. Dent. J. 2016; 62: 225-34.

21. El-Mangoury NH, Mostafa YA. Epidemiologic panorama of dental occlusion. Angle Orthod 1990;60:207-14. 
22. Abd ElMotaleb M, Al Dakroury A, Sharaby F. Prevalence of Anterior Open Bite Among Egyptian Adolescent Population. Aust. J. Basic \& Appl. Sci. 2014;8: 533-37.

23. Alhammadi MS, Halboub E, Fayed MS, Labib A, El-Saaidi C. Global distribution of malocclusion traits: A systematic review. Dental Press J Orthod. 2018;23:40.e1-10.

24. Almalky MN, Elattar MH. Prevalence of different types of malocclusion among school children in Makkah Governorate of Saudi Arabia. Int J Dentistry Oral Sci. [Internet] 2018 June [cited 2018 Sep ;5(6):645-648. Available from: http://dx.doi.org/10.19070/2377-8075-18000127

25. Jamil D, Anne NA, Nina JW. Prevalence and correlates of self-reported state of teeth among schoolchildren in Kerala, India. BMC Oral Health 2006;6:10-8.

26. Angle EH. Classification of malocclusion. Dental Cosmos. 1899;41:24864.

27. Tsai HH. Components of anterior crossbite in the primary dentition. J Dent Child. 2001;68::27-32. PMid:11324403 22.

28. Björk A, Krebs A, Solow B. A method for epidemiological registration of malocclusion. Acta Odontol Scand. 1964; 22:28-40.

29. Baum AT. The midline diastema. J Oral Med. 1966;21:30-9.

30. Graber TM: Orthodontics- Principles and Practice. $3^{\text {rd }}$ ed. Philadelphia: WB Saunders, 86-124, 180-203, 1972

31. Proffit WR, Fields HW Jr, Moray LJ. Prevalence of malocclusion and orthodontic treatment need in the United States: Estimates from the NHANES III survey. Int J Adult Orthodon Orthognath Surg. 1998;13:97-106.

32. Baeshen $\mathrm{H}$. The prevalence of major types of occlusal anomalies among Saudi
Middle school students. J Contemp Dent Pract. 2017; 18:142-6.

33. Behbehani F, Artun J, Al-Jame B, Kerosuo H. Prevalence and severity of malocclusion in adolescent Kuwaitis. Med Princ Pract. 2005;14:390-5.

34. Abu Alhaija ES1, Al-Khateeb SN, AlNimri KS. Prevalence of malocclusion in 1315-year-old North Jordanian school children. Community Dent Health. 2005;22:266-71.

35. Bugaighis I, Karanth D. The prevalence of malocclusion in urban Libyan schoolchildren. J Orthodont Sci. 2013;2:1-6.

36. Shrestha $\mathrm{S}$, ShresthaRM. An analysis of Malocclusion and occlusal characteristics in Nepalese orthodontic patients. Orthod J Nepal. 2013;3:19-25.

37. Nadim R, Aslam $\mathrm{K}$, Rizwan $\mathrm{S}$. Frequency of Malocclusion among 12-15 years old school children in three sectors of Karachi. Pakistan Oral Dent J. 2014;34:510-14. 38. Aikins EA, Onyeaso CO. Prevalence of malocclusion and occlusal traits among adolescents and young adults in Rivers State, Nigeria. Odontostomatol Trop 2014;37:5-12.

39. Borzabadi-Farahani A, Borzabadi-Farahani A, Eslamipour F. Malocclusion and occlusal traits in an urban Iranian population. An epidemiological study of 11- to 14-year-old children. Eur J Orthod 2009;31:477-84.

40. Omutimba DS, Ramadan AA, Refaat WE. Prevalence of different classes of malocclusion among dental students at Moi University in Kenya. Alex Dent J. 2016;41:1-3.

Celikoglu M, Akpinar S, Yavuz I. The pattern of malocclusion in a sample of orthodontic patients from Turkey. Med Oral Patol Oral Cir Bucal. 2010;15:791-6. 